Bulletin of Pharmaceutical Sciences
Assiut University
$\begin{gathered}\text { Website: } \text { http:///bsa.journals.ekb.eg/ } \\ \text { e-mail: bullpharm@aun.edu.eg }\end{gathered}$

\title{
THE STATUS OF COMMUNITY PHARMACY IN EGYPT: ARE COMMUNITY PHARMACIES READY TO DELIVER CLINICAL PHARMACY SERVICES AT THE NATIONAL LEVEL?
}

\author{
Mohamed M. M. Abdel-Latif ${ }^{1 *}$, Sahar B. Hassan ${ }^{1}$ and Kamal Sabra ${ }^{2}$ \\ ${ }^{1}$ Department of Clinical Pharmacy, Faculty of Pharmacy, Assiut University, Assiut, Egypt \\ ${ }^{2}$ School of Pharmacy, University College Cork and Faculty of Health Sciences, Trinity College \\ Dublin, Ireland, and Future University, Egypt
}

\begin{abstract}
Pharmacy practice is witnessing considerable changes in concept and practice in Egypt in recent years. Egypt has the highest number of pharmacists per capita and community pharmacies in the Middle East and North Africa region. Literally, all medicines are freely sold without a prescription irrespective of their status as prescription drugs or over-the-counter drugs; and the pharmacist plays a key role in recommending basic medicines to the public. Community pharmacies are widely distributed throughout the country and more accessible healthcare facility to the community that offering clinical, diagnostic and public health services. The concept of pharmaceutical care has not also been acknowledged yet at community pharmacies; and most community pharmacies lack computerized systems and modern technologies, as well as lack of qualified pharmacists who could deliver clinical pharmacy services. Despite laws and regulations exist; there is a lack of enforcement of those regulations to ensure good pharmacy practice at community pharmacies. The aim of the review was to describe the current status of community pharmacy in Egypt and their preparedness to deliver clinical pharmacy services.
\end{abstract}

\section{INTRODUCTION}

\section{Healthcare system in Egypt}

Egypt is the largest Arab lower middleincome country in the Middle East and North Africa region of over 100 million people $e^{1 \& 2}$. Egypt has a diverse healthcare system consists of two sectors: public and private. The governing body of Egypt's healthcare system is the Ministry of Health and Population (MoHP) which runs a nationwide healthcare system of health services ranging from large urban hospitals to outpatient clinics, providing a mixture of inpatient and outpatient care ${ }^{3}$. The performance of the health system in Egypt was ranked $63^{\text {rd }}$ among 191 countries according to the World Health Organization's ranking of the world's health systems ${ }^{4}$. There is an increase in health demands, with a wide spread of chronic diseases, complex treatment regimens and poor adherence to prescribed medicines, has forced pharmacists to take a patient-oriented approach.

Generally, Egyptians prefer to see private physician for medical treatment and outpatient care. The majority of inpatient beds are located in public medical facilities (public hospitals, university hospitals, military hospitals). The private sector includes profit and non-profit organizations and provides all health services such as private hospitals, private doctors, traditional midwives, charitable organizations, religiously affiliated clinics and private pharmacies. The healthcare system in Egypt is highly fragmented health system and faces multiple challenges in improving and ensuring quality and standards of healthcare of people ${ }^{4}$. The problem is not only the burden of combating illness with poverty and lack of education, the burden of health financing,

Received in 10/1/2021 \& Accepted in 12/2/2021 
unequal access to health services but also tackling the emerging diseases associated with modern and urban lifestyle ${ }^{5}$. Egyptians still prefer traditional remedies especially the rural poor and many individuals rely on homeopathic cures in certain cases as well as seeking a selfmedication for minor illnesses or medical advice of health problems from community pharmacies. In many developing countries like Egypt, community pharmacies are the main source of drugs. The majority of drugs were dispensed without a prescription or advice from pharmacists ${ }^{6}$. However, flaws in the prescribing practices and in the over-thecounter prescribing and medical advice from pharmacists have been identified ${ }^{7-9}$. These fallouts raise stressing questions about the presence of skilled pharmacists, availability of drug information and promoting rational drug use.

Egypt as a developing country with limited health budget and lack of education about appropriate use of medicines faces many challenges in providing medical care. The spending on medical care and medicines mostly comes from out-of-pocket payments. The pharmaceutical industry and the drug market in Egypt is a major player in the health care system and the pharmacist makes a greater contribution to providing primary health care. In developing countries the decision of which medicine the consumer purchases may be different than in developed countries, where the physician is presumed to be the influential decision-maker in the medicines prescribed. In general, Egyptian people are free to enter any retail pharmacy and purchase any drug in any quantity. Therefore, the pharmacist not only dispenses medicines but also plays a powerful role in helping patients guiding and choosing the best drug. While Egyptian laws prohibiting the dispensing of drugs without a physician's prescription; these laws are ignored by the pharmacist, the patient and the regulators.

\section{Community pharmacy in Egypt}

Community pharmacies are widely available throughout Egypt of different types including independent pharmacy, chain pharmacy, mass merchandiser pharmacy and natural pharmacy. The community pharmacy is the front door for many people in Egypt for the sake of medical treatment and health advice.
Obviously, the pharmacists are more accessible and friendly to patients than doctors to get medical treatment. Many community pharmacies operate 24-hour services and pharmacies provide home delivery. People cannot afford to go to private clinics or hospitals for seeking treatment due to the cost of charge, long waiting hours and insurance; they instead can approach community pharmacies to receive information on medical conditions and medicines. Therefore, the role of the community pharmacist is critical in community settings to deliver patient care. This necessitates that the community pharmacists should have appropriate scientific knowledge and clinical skills to deliver patient care.

Community pharmacies are distributed all areas of Egypt. The ownership of community pharmacies in Egypt is not limited to pharmacists and the pharmacist is allowed to own two pharmacies. A community pharmacy must be managed by a registered pharmacist after 1 year in practice as a provisionally registered pharmacist. Under law, a pharmacist has to be present when the pharmacy is open, but this factually is not true where nonpharmacists can dispense and supply medicines to the customers.

Over the past decades there has been a substantial rise in the chain ownership of community pharmacies in Egypt. However, there is an ongoing dispute for years between the owners of chain pharmacies in Egyptian market and the Egyptian pharmacists syndicate about their legal presence. Of a particular note, chain pharmacies are entities present in most countries worldwide.

One of the biggest problems facing the community pharmacy in Egypt is the large increase in their number as well as the increase owing to large numbers of pharmacy graduates in the last years ${ }^{10 \& 11}$. This problem is further complicated by the rise in property prices in the last years. There is also a less competitive salary scale of community pharmacists and absence of a motivating career pathway compared to hospital pharmacy and other pharmacy careers ${ }^{11}$.

\section{Community pharmacy services}

The community pharmacy nowadays greatly depends on the trading services rather than the delivery of clinical services. 
Community pharmacy concentrates on profit over provision of professional services. Most community pharmacy services offered are basic and customary services including dispensing of prescriptions and extemporaneous preparation. Patients can approach the pharmacist for seeking medical advice about many illnesses; and the pharmacist recommends both prescription drugs and over-the-counter or "non-prescription" drugs when responding to the patient's minor ailments. Moreover, the pharmacist performs diagnostic tests to monitor disease control, such as blood pressure, blood sugar, and cholesterol monitoring. The pharmacist can also perform public health activities including smoking cessation, healthy nutrition and dieting, combating drug abuse and health education and promotion.

In Egypt, as in many developing countries, medications can easily be obtained over-thecounter which represents a serious public health problem ${ }^{6,7,12-15}$. The over-the-counter drugs are generally used in the practice of responsible self-medication for their safety and effectiveness; however, a pitfall to this practice in Egypt is that prescription drugs are commonly dispensed without a prescription. The common reasons behind self-medication were the rapid access to pharmacy services and moneywise issues to reduce cost to save money and avoid long waiting times in hospitals and physicians' clinics.

The introduction of the clinical pharmacy program in some faculties of pharmacy may help to pharmacy graduates with appropriate knowledge and skills to reduce the problem of self-medication among population. Furthermore, there is a need for increasing awareness of the public about the dangers of self-medication as well as developing proper legislation and regulations.

Egypt's pharmaceutical sales are largely dependent on prescription sales, which comprised $82.5 \%$ of total drug sales in 2016 as compared to $17.5 \%$ over-the-counter products of the total pharmaceutical expenditure ${ }^{16}$. The pharmaceutical sales and payment to community pharmacies are based on out-ofpocket expenditures as consumers find selfmedication to be the cheapest form of treatment and sometimes may be covered by the national health insurance program in designated community pharmacies. In 2014, Egypt approved its list of prescription-only medicines and over-the-counter products for better regulation and enforcement of legislative laws ${ }^{11}$. Such referenced list would aid community pharmacists in making appropriate selection of over-the-counter drugs and ensuring patient safety.

\section{Pharmacist's roles in community pharmacy}

The role of the pharmacist has evolved from product-focused to patient-oriented services ${ }^{17}$. This paradigm shift for pharmacy practice took place in 1990, when Hepler and Strand introduced the philosophy of pharmaceutical care ${ }^{18}$. The pharmaceutical care concept has transformed the pharmacy profession to play a major role in patient care to achieve positive drug therapy outcomes ${ }^{19}$. It is believed that pharmacists can make a great contribution to the provision of pharmaceutical care services in primary healthcare ${ }^{20}$. The pharmacist works long hours and sees patients more often than physicians do; therefore, pharmacists are in a superior position to take on the role of primary healthcare providers to meet the need for better healthcare. The World Health Organization suggested that the future pharmacist should be educated to take a lead in the management of minor ailments and to have additional skills for an expanded role ${ }^{21}$.

The pharmacist's job as a health caregiver and drug advisor in any society is so important in today's healthcare system. The pharmacist has an essential role in the healthcare system whereas healthcare providers use pharmacists as a source of drug information, especially drug interactions and medication errors. In developing countries like Egypt with large populations living at or below the poverty level, the pharmacist may be not only the most important source of drug information but may influence the decision of which medicine the consumer purchases for multitudes of consumers. Pharmacists regularly recommend over-the-counter medications; however, dispensing without a prescription remains a serious problem in Egypt, as in many other countries in the Middle East region ${ }^{22-24}$. Many populations who cannot afford doctor appointments may call to the pharmacy for medical advice or drug treatment in extreme situations; and also those who can afford doctor visits may also call for self-medication. 
For common ailments, individuals ask the pharmacist for a medical advice or a specific medication for themselves or someone else minor symptoms. Despite there are Egyptian laws prohibiting the dispensing of drugs without a prescription, these laws are generally violated by the pharmacists and the prescribers. Any individual can freely enter any pharmacy and purchase any drug in any quantity. Furthermore, the pharmacist not only dispenses medicines but also administers injections in the pharmacy.

\section{Number of community pharmacies and pharmacists}

Egypt has the highest proportion of the pharmacy workforce working in community settings. These numbers definitely exceed the international figures. According to Egyptian pharmacists syndicate records, there are approximately 216,072 registered pharmacists; this number constitutes about 4-times of the international figures ${ }^{10 \& 11}$. On average there is one pharmacist for 438 citizen ( 23 pharmacist for 10000 citizen) compared to one pharmacist for 1100-1600 citizen (6-9 pharmacists for 10000 citizen). According to Egyptian pharmacists syndicate records, there are approximately 75,165 community pharmacies; this number constitutes about three-times of the international figures. This means that one pharmacy for 1261 citizen (8 pharmacies for 10000 citizen) compared to one pharmacy for 3500-5000 citizen (2-3 pharmacy for 10000 (itizen) $)^{10 \& 11}$.

On the other hand, the number of doctors is approximately 280,000 , whereas there is about one pharmacist for 1.5 doctors compared to one pharmacist for 11 doctors internationally, and one pharmacy for every 5 doctors $^{25}$. Moreover, a greater number of pharmacists are employed across the region, particularly in the Gulf region ${ }^{26}$.

Egypt has the largest number of pharmacy faculties among countries in the Middle East; currently there are 44 faculty of pharmacy ${ }^{11 \& 26}$. Egypt has the fourth highest number of pharmacists per capita in the world, after Malta, Japan and Jordan ${ }^{11}$. According to estimated data, there is about 14573 in the year of 2017 newly pharmacy graduates per year $^{10 \& 11}$. Countries with higher densities of pharmacists also tend to have higher densities of pharmacies. A survey of 56 countries revealed negative correlations were observed with density of pharmacist per capita population and proportion of the workforce in academia $^{27}$. Conversely, positive associations are present with entry into community pharmacy careers. Four countries from the survey produced more than 8,000 graduates in total each year (Brazil, Japan, Egypt and USA). Among these countries, Egypt had the highest number of ratio of graduates to schools of pharmacy.

\section{Interaction between pharmacists and physicians in community settings}

The role of community pharmacists has been traditionally characterized by dispensing prescription medicines, selling over-the-counter medication and sometimes offering healthcare advice. Community pharmacist is not seen as a member of the healthcare team. The acceptance of community pharmacist as a healthcare provider by the doctors and patients is questionable. Furthermore, there is no or little direct contact between community pharmacists and general practitioners. In addition, the attitudes of doctors towards pharmacists and their contribution to better medication management is another barrier to overcome ${ }^{28}$. Some physicians are skeptical about the expanded role for community pharmacists in primary healthcare, opposing pharmacy as the first point of call for treating minor ailments and disease state management. Interestingly, people will continue to consult community pharmacists for minor illnesses as they are an accessible source of information and advice. The roles between community pharmacists and doctors should be synchronizing; and a better healthcare system requires a collaborative work among all healthcare professionals to deliver optimum patient care.

\section{Challenges in community pharmacy practice}

There are a number of problems facing the pharmacy practice in community pharmacies, here; we describe some of these challenges:

\section{Inadequate clinical expertise of community pharmacists}

One of the most barriers facing most pharmacists in community is the focus of the pharmacists on the sale of a product rather than 
provision of services. Many pharmacists lack adequate clinical pharmacy skills and practical knowledge in communicating with physicians and patients. Moreover, the level of clinical services provided varies greatly among community pharmacies and among pharmacists. Egyptian pharmacists syndicate and pharmaceutical organizations run irregular training programs but they are insufficient to equip the pharmacists with the clinical knowledge to perform their duties. Furthermore, the hospital pharmacy administration has also established a clinical pharmacy fellowship training program in Egypt to develop clinical skills and advance clinical practice through working collaboratively with the multidisciplinary team to achieve the best medication management outcomes for patients $^{29}$.

\section{Pharmacist-physician interaction and patient beliefs}

The relationship between the physicians and pharmacists is complex, and physicians have been uncomfortable with pharmacists providing direct patient care ${ }^{30}$. The physicianpharmacist interaction is a key factor in the medication use process to ensure medication and patient safety. Since a long time ago, the physicians have enjoyed a dominant position within the healthcare professionals, and it has become a mandatory that physicians should be educated about the clinical role of the pharmacists regarding drug therapy and patient counselling ${ }^{30}$. Pharmacists are un-reluctant to challenge physicians regarding prescribing errors and drug information and see themselves incompetent compared to physicians. Furthermore, many patients are unaware of the role of pharmacists in providing medicines information, drug interactions, side effects and instructions about medications use. Patients believe that physicians know more than pharmacists about their drug therapy.

\section{Pharmacist availability}

Despite the high number of the Egyptian pharmacists to the number of population compared to the international figures, the availability of the pharmacists in community pharmacies is questionable. It is unusual to find a pharmacist in many community pharmacies, which dramatically affect on the level of pharmaceutical care provided in these facilities. Unfortunately, in many circumstances, absence of pharmacists and their roles being performed by the non-qualified personnel working at community pharmacies are a common practice $^{11}$. Furthermore, the distribution of pharmacists and services provided by pharmacies and pharmacists are diverse in Egyptian governorates. This factor will deem to be of a great threat to implementing of clinical pharmacy services in community settings.

\section{Standards of clinical pharmacy practice in community pharmacy}

Community pharmacy is the largest sector of pharmacy practice in Egypt. Much progress has been made in relation to the practice of pharmacy in hospital settings; as the inauguration of many clinical pharmacy units and drug information centers in many different hospitals $^{30 \& 31}$. The hospital pharmacy administration at the Central Administration for Pharmaceutical Affairs has introduced guidelines and standards for proper application and practice of clinical pharmacy in Egyptian hospitals and the necessary documentation involved $^{32}$. Despite the successful movement to the introduction clinical pharmacy in Egyptians hospitals, clinical pharmacy practice in community pharmacy settings is still primitive and requires setting national standards and legislative guidelines regarding good community pharmacy practice, counseling area, electronic patient records and pharmaceutical training programs.

\section{Lack of privacy and patient confidentially}

Many community pharmacies are small, crowded and do not have private area, which discourage patients from seeking medicines information from pharmacists. In addition, in this crowded environment, patients feel uncomfortable to ask questions. In 2009, a ministerial decree (380) was issued to increase pharmacy area to 40 meters as a minimum space to license a pharmacy to accommodate the large number of medicines and toiletry products and also to provide a private area for patient counselling. Unfortunately, this decision was cancelled by another ministerial decree (198) in 2011 and pharmacy area was returned back to its original space of 25 meters as this decision was opposed by the Egyptian 
pharmacists syndicate and newly graduated pharmacists $^{11}$.

Healthcare authorities should promote the development of electronic program and technological tools that provide community pharmacists with patients-specific data, medications history in order to provide clinical pharmacy services and pharmaceutical care. Pharmacies must also develop appropriate methods to interact with physicians when necessary for the patients whom they serve and to receive diagnostic and laboratory information.

\section{Drug information resources}

Although the internet is emerging as an important source of medical information, but patients still have a number of questions about their medical conditions and medications. Many patients seek medical advice directly from the community pharmacies particularly urban areas because community pharmacies are accessible and less expensive than the physician's as well as medical services are less developed. Therefore, the community pharmacist has a great opportunity to provide drug information for patients. In many community pharmacies, the traditional drug information references are unavailable and electronic resources are lacking. Nowadays, it is becoming important that all community pharmacies should have basic drug information resources to correctly answer drug-related questions and patient-related queries.

\section{Continuing pharmaceutical education}

Continuing pharmaceutical education program is not offered on a frequent basis which would be extremely important for pharmacists to advance their clinical knowledge to accomplish their professional roles towards the patients. Mandatory continuing education that includes rational use of medicines is not required for pharmacists, and there is no professional examination in place to assess the current knowledge of the pharmacists. Community pharmacists have been reported to attend fewer continuing education events compared to hospital pharmacists in Egypt $^{33}$. Egyptian pharmaceutical bodies and faculties of pharmacy should embrace pharmaceutical educational programs for community pharmacists to maximize their clinical knowledge and skills towards the provision of patient care. These programmes should address limitation on information available to pharmacists and gaps in pharmacy practice.

\section{Law and legislation barriers}

Irrational use of medicine and weak regulatory enforcement of drug sales are serious problems in Egypt. The laws and regulations covering various aspects of community pharmacy such as licensing, supply of medicines, storage, transportation, inspection and information systems need revision. Most pharmacists have little or no pharmaceutical continuing education for years and also people buy drugs without prescriptions. In addition, the non-professional staffs in community pharmacies are another major issue contributed to drug problems and medications misuse. Some regulatory laws were issued in 2009 regarding the space of pharmacy outlet and setting a private counseling area in community pharmacies but unfortunately this movement instead of being welcomed by pharmacists to deliver pharmaceutical care and patient counseling but faced a lot of opposition from pharmacists themselves and pharmaceutical bodies.

Patient safety and accountability for the outcomes of drug therapy have become a main focus of attention. Countries like USA and UK frequently are working for assessment of pharmacists' skills and competencies for delivering pharmaceutical services. A UK study on the incidence, nature and cause of dispensing errors in community pharmacies estimated that on average, for every 10,000 items dispensed there are approximately 22 near misses and 4 dispensing errors ${ }^{34}$. It has been estimated that on average, a pharmacist will make a dispensing error every month ${ }^{35}$. While not all of these errors are serious enough to cause death or injury, the fact remains errors can so easily be made, even by the best pharmacists and with the best practices as errors usually result from distraction or loss of concentration. In UK, a pharmacist was suspended from the register for three months by the General Pharmaceutical Council after making dispensing errors, dispensing methadone without a prescription and attempting to delete patient medication 
records ${ }^{36}$. A British pharmacist was also sentenced to a three-month jail sentence, suspended for 18 months, following a dispensing error of the wrong medicine mistakenly ${ }^{37}$. The licenses of a pharmacist and his specialty pharmacy have been suspended for compounding medicine without individual patient prescriptions ${ }^{38}$.

The fitness to practice function is one of the regulatory systems of pharmaceutical societies of UK and Ireland aimed at protecting the public interest and safeguarding patient welfare. Several cases of suspension or sanctions were reported in many countries. Two London community pharmacists who sold prescription-only antibiotics to an undercover reporter have been suspended from the register for 12 months following fitness-to-practice (FTP) hearings ${ }^{39}$. A pharmacist who accepted a police caution for the unlawful possession of cocaine and who failed to inform the Registrar of the fact has been suspended from the Register for six months, by order of the fitnessto-practice committee of the General Pharmaceutical Council ${ }^{40}$. Misconduct and deficient professional performance have resulted in a pharmacist's 12-month suspension from the Register, by order of the Fitness-toPractice Committee of the General Pharmaceutical Council ${ }^{41}$. A 12-month suspension order has been handed by the fitness-to-practice committee of the General Pharmaceutical Council to a pharmacist convicted of indecent exposure ${ }^{42}$. Photocopying confidential financial information relating to the pharmacy where he worked as a locum has led to the suspension of a pharmacist from the Register for two months, by order of the fitness-to-practice committee of the General Pharmaceutical Council ${ }^{43}$. Pharmacist who molested female staff members suspended for one year ${ }^{44}$. A dispensing error involving morphine slow release tablets (MST) has resulted in the fitness-to-practice committee of the General Pharmaceutical Council handing a two-month suspension from the Register to a Yorkshire pharmacist ${ }^{45}$. In Ireland, a senior pharmacist is to be sanctioned for dispensing the wrong brand of one medicine and the incorrect dosage of another ${ }^{46}$.

In a country like Egypt with the highest number of community pharmacists and hundreds of off-street drugs sold without strict regulations in place, there were little reports about misconduct, suspension, sanction or deregistration published by pharmaceutical bodies and drug authorities. Community pharmacists must work professionally and legally to ensure that they provide an effective and safe pharmaceutical care for their patients. The pharmaceutical regulators have to take rigorous steps towards the implementation of legislative changes in community pharmacy.

\section{Conclusions and recommendations}

Community pharmacy practice in Egypt is regulated under the Ministry of Health (MoHP) at the national level and the Egyptian Drug Authority (EDA). Medicines in Egypt are irrationally used by patients and the public resulting in drug-related problems of various magnitudes, therefore, community pharmacists have the potential to not only contribute to improving patients' outcomes, but also to reduce the healthcare costs by resolving drugrelated problems and promoting public health. Furthermore, the community pharmacists have a great opportunity to deliver pharmaceutical care to many people who are poor and illiterate.

We strongly believe that the introduction of professional clinical pharmacy services in community pharmacies can greatly minimise drug-related problems and advance good pharmacy practice. However, important barriers to the provision of pharmaceutical care in community pharmacies exists including absence of counseling area, lack of privacy, unskilled pharmacists, weak implementation of existing laws, and lack of recognition of the pharmacy as a clinical profession by other healthcare professionals. Therefore, it is necessary to enhance the interprofessional collaboration and communication between physicians and pharmacists; as well promotion of the rational use of medicines and good prescribing practice. The majority of faculties of pharmacy lack experiential training and clinical competencies to develop pharmacy graduate attributes and professional skills for clinical practice. Moreover, most community pharmacists attend fewer continuing pharmaceutical education events compared to hospital pharmacists.

We also strongly call for the introduction of legislative regulations and professional 
standards at the national level to create a more professional climate for the community pharmacy practice. Policy makers and pharmacy organizations also face complexity in attempting to contain and utilize the pharmacy graduates, while maintaining pharmacists' competence and advancing the profession. It is important to keep tracking such changes to see the impact in the future as a profession and a practice. Furthermore, there is a gap exists between the career pathway for community pharmacists and pharmacists in the industry or hospital settings, as well as the less competitive salary structure of community pharmacists and absence of a motivating career pathway. Many pharmacists pursue self-learning and engage in postgraduate programs including American board certification in pharmacotherapy and nutrition, clinical pharmacy fellowship, pharmacy doctorate program, and clinical pharmacy diploma offered at many universities.

As pharmacy moves towards advanced practice and the complexity of professionalism, the educators should start considering curriculum mapping and experiential learning to advance pharmacy education and practice proficiency. Recently, the Ministry of Higher Education and Scientific Research (MHESR) in collaboration with the Ministry of Health and Population (MoHP) are seeking to mandate a recertification examination for pharmacists to enforce staying up-to-date with the professional knowledge and skills.

Recognizing that the community pharmacist is the closest and accessible healthcare professional, it is becoming a mandatory that his role should be expanded in developing countries like Egypt to better serve the patients and benefit the society. Therefore, there is a need for greater professional education and greater expertise for the pharmacists to help their patients and to make safe and effective medicines use. Future research should address the role of the community pharmacists and the interprofessional collaboration between the pharmacists and physician in delivering healthcare services as well as understanding the motivations behind pharmacists influence and medicine prescribing.

\section{REFERENCES}

1- The World Bank, "How We Classify Countries", (2020), Available at https://data.worldbank.org/country/EG.

2- Central Agency for Public Mobilization and Statistics (CAPMAS), "The Egyptian Population", Cairo, (2020), Available at https://www.capmas.gov.eg.

3- Ministry of Health and Population, Available at https://www.egypt.gov.eg/ Arabic/Home.aspx

4- World Health Organization, World Health Report (2000), Measuring Overall Health System Performance for 191 Countries, Geneva, (2000), Available at https:// www.who.int/healthinfo/paper30.pdf.

5- World Health Organization, (2020), Available at: http://www.emro.who.int/ egy/programmes/health-systemsstrengthening.html

6- H. Benjamin, F. Smith and M. A. Motawi, "Drugs dispensed with and without a prescription from community pharmacies in a conurbation in Egypt", Eastern Mediterranean Health Journal, 2 (3), 506-514 (1996).

7- K. Kasim and H. Hassan, "Self medication problem in Egypt: A review of current and future perspective", International Journal of Current Research and Review, 10 (4), 40-45 (2018).

8- S. S. Sansgiry, A. H. Bhansali, S. S. Bapat and X. Qingqing, "Abuse of over-thecounter medicines: A pharmacist's perspective", Integrated Pharmacy Research and Practice, 6, 1-6 (2017).

9- M. E. Ruiz, "Risks of self-medication practices", Current Drug Safety, 5 (4), 315-23 (2010).

10- Egyptian Pharmacists Syndicate (2020), Available at: http://www.eps-egypt.net/.

11- A. Fathelrahman, M. Ibrahim and A. I. Wertheimer, "Pharmacy Practice in Developing Countries: Achievements and Challenges", United Kingdom, $1^{\text {st }}$ Edn., Academic Press, 2016, pp. 291-317.

12- N. Sabry, S. Farid and D. M. Dawoud, "Antibiotic dispensing in Egyptian community pharmacies: An observational study", Research in Social and 
Administrative Pharmacy, 10 (1), 168184 (2014).

13- N. M. Kamal Elden, H. A. Nasser, A. Alli, N. Mahmoud, M. A. Shawky, A. A. A. Ibrahim and A. K. Fahmy, "Risk factors of antibiotics self-medication practices among university students in Cairo, Egypt", Macedonian Journal of Medical Sciences, 8 (E), 7-12 (2020).

14- N. A. El-Nimr, I. M. Wahdan, A. M. Wahdan and R. E. Kotb, "Self-medication with drugs and complementary and alternative medicines in Alexandria, Egypt: Prevalence, patterns and determinants", Eastern Mediterranean Health Journal, 21 (4), 256-265 (2015).

15- S. A. Sallam, N. M. Khallafallah, U. K. Ibrahim and A. O. Okasha, Pharmacoepidemiological study of self medication in adults attending pharmacies in Alexandria in Egypt", Eastern Mediterranean Health Journal, 15, 683691 (2009).

16- NGAGE consulting. Egypt's Pharmaceutical Sector Following Bold Economic Reforms: Challenges and Opportunities. Cairo, Egypt (2017), Available at https://www.ngageconsulting.com/downloads/Pharmaceutica 1_PDF_Final_Version_K_and_A.pdf

17- World Health Organization, "New Tool to Enhance Role of Pharmacists in Health Care", (2020). Available at: http://www.who.int/mediacentre/news/ne w/2006/nw05/en/index.html.

18- C. Hepler and L. Strand, "Opportunities and responsibilities in pharmaceutical care", Journal of Hospital Pharmacy, 47, 533-543 (1990).

19- K. B. Farris, F. Fernandez-Llimos and S. I. Benrimoj, "Pharmaceutical care in community pharmacies: Practice and research from around the world", Annals of Pharmacotherapy, 39, 1539-1541 (2005).

20- J. Jesson and P. Bissell, "Public health and pharmacy: A critical review", Critical Public Health, 16, 159-169 (2006).

21- World Health Organization, The Role of the Pharmacist in the Health Care System: Preparing the Future Pharmacist:
Curricular Development: Report of a Third WHO Consultative Group on the Role of the Pharmacist, Vancouver, Canada, 27-29 August (1997). Available at https://apps.who.int/iris/handle/ $10665 / 63817$

22- S. A. Bawazir, "Prescribing pattern at community pharmacies in Saudi Arabia", International Journal of Pharmacy, 6, 222-224 (1992).

23- A. Abuirmeileh, S. Samara, A. Alkhodari, A. Bahnassi, A. Talhouni and A. M. Hayallah, "Antibiotic dispensing without prescription in Jordanian community pharmacies: A pharmacist's perspective", Bulletin of Pharmaceutical Sciences Assiut University, 37, 51-63 (2014).

24- S. Hasan, H. Sulieman, C. Chapman, K. Stewart and D. C. Kong, "Community pharmacy in the United Arab Emirates: Characteristics and workforce issues", International Journal of Pharmacy Practice, 19 (6), 392-399 (2011).

25- Egypt Pharmaceutical Country Profile, Ministry of Health Egypt in collaboration with the World Health Organization. July (2011). Available at https://www.who.int/ medicines/areas/coordination/Egypt_PSC PNarrativeQuestionnaire_27112011.pdf?u $\mathrm{a}=1$.

26- N. Kheir, M. Zaidan, H. Younes, M. E. Hajj, K. Wilbur and P. J. Jewesson, "Pharmacy education and practice in 13 Middle Eastern countries", American Journal of Pharmaceutical Education, 72 (6), Article 133 (2008).

27- C. Anderson, I. Bates, A. Bruno, B. Futter, M. J. Rouse and S. Whitmarsh, "FIP Global Pharmacy Workforce Report", (2009). Available at https://www.fip.org/

files/fip/PharmacyEducation/Pharmacy $\% 2$ 0Education.pdf.

28- F. Bradley, R. Elvey, D. M. Ashcroft, K. Hassell, J. Kendall, B. Sibbald and P. Noyce, "The challenge of integrating community pharmacists into the primary health care team: a case study of local pharmaceutical services (LPS) pilots and 
interprofessional collaboration", Journal of Interprofessional Care, 22, 387-98 (2008).

29- Egyptian Clinical Pharmacy Fellowship: Ministry of Health and Population (2020), Available at https://eda.mohp.gov.eg/ Pharma/Clinical.aspx?Main=Services $\&$ Se rviceid $=5 \&$ Sub main $=$ serv16; 2014.

30- M. M. Abdel-Latif and K. Sabra, "Clinical pharmacy practice in Egyptian hospitals", American Journal of Health-System Pharmacists, 73 (1), e63-66 (2016).

31- Central Administration of Pharmaceutical Affairs (CAPA), Hospital Pharmacy Administration, Egyptian Clinical Pharmacy Standards of Practice (2014), Available at https://eda.mohp.gov.eg/ Files/409_Egyptian_clinical_pharmacy_st andards_E.pdf.

32- National Health Accounts 2007-2008: Egypt Report. In: Health systems 20/20 project, Bethesda (MD): Abt Associate Inc. (2010). Available at https://www.hfgproject.org/wpcontent/uploads/2015/02/National-HealthAccounts-2007-2008_Egypt-Report.pdf

33- O. H. M. Ibrahim, "Assessment of Egyptian pharmacists' attitude, behaviors, and preferences related to continuing education", International Journal of Clinical Pharmacy, 34 (2), 358-363 (2012).

34- D. E. Roberts, M. G. Spencer, R. Burfield and S. Bowden, "An analysis of dispensing errors in NHS hospitals", International Journal of Pharmacy Practice, 10 (Suppl), R6 (2002).

35- D. Ashcroft, C. Morecroft, D. Parker and P. Noyce, "Patient Safety in Community Pharmacy: Understanding Errors and Managing Risk" (Final report to the Community Pharmacy Research Condortium. University of Manchester), London: Royal Pharmaceutical Society of Great Britain (2005).

36- Chemist and Druggist. Pharmacist Suspended After Making Dispensing Errors and Deleting Records, (2012), Available at https://www. Chemistanddruggist.co.uk/news/pharmaci st-suspended-after-making-dispensing- errors-and-deleting-records\#sthash.

RIdmYiEt.dpuf.

37- The Pharmaceutical Journal, Former Locum Handed Suspended Jail Term for Dispensing Error, (2009), Available at https://www.pharmaceutical-journal.com/ news-and-analysis/former-locum-handedsuspended-jail-term-for-dispensingerror/10882780.article.

38- USA TODAY. Compounding Pharmacist's License Suspended, (2014), Available https://www.usatoday.com/story/news/nati on/2014/02/19/compounding-pharmacistslicense-suspended/5628353.

39- The Pharmaceutical Journal, (2012), Available at https://www.pharmaceuticaljournal.com/searcharticles?keywords=sus pension+or+sanction+of+pharmacists.

40- The Pharmaceutical Journal, Failure to Inform Registrar of Caution Results in Pharmacist's Six-Month Suspension, (2012), Available at https://www. pharmaceutical-journal.com/news-andanalysis/news/failure-to-inform-registrarof-caution-results-in-pharmacists-sixmonth-suspension/11097674.article

41- The Pharmaceutical Journal, Poor Professional Performance Leads to 12Month Suspension, (2012), Available at https://www.pharmaceutical-journal.com/ news-and-analysis/news/poorprofessional-performance-leads-to-12month-suspension/11104951.article.

42- The Pharmaceutical Journal, Pharmacist's 12-Month Suspension for Indecent Exposure, (2013), Available at https:// www.pharmaceutical-journal.com/newsand-analysis/news/pharmacists-12-monthsuspension-for-indecent-exposure/ 11116400.article.

43- The Pharmaceutical Journal, Locum Pharmacist Suspended for Two Months After Photocopying Confidential Information, (2012), Available at https://www.pharmaceutical-journal.com/ news-and-analysis/news/locumpharmacist-suspended-for-two-monthsafter-photocopying-confidentialinformation/11097672.article. 
44- The Pharmaceutical Journal, Pharmacist Who Molested Female Staff Members Suspended for One Year, (2011), Available at https://www.pharmaceuticaljournal.com/news-and-analysis/ announcement/pharmacist-who-molestedfemale-staff-members-suspended-for-oneyear/11074179.article.

45- The Pharmaceutical Journal, Two-Month Suspension for Responsible Pharmacist
After Dispensing Error, (2013), Available at https://www.pharmaceutical-journal. com/news-and-analysis/news/two-monthsuspension-for-responsible-pharmacistafter-dispensing-error/11124650.article.

46- Irish Independent, Pharmacist Faces Sanction Over Errors, (2013), Available at https://www.independent.ie/irish-news/ pharmacist-faces-sanction-over-errors28958547.html. 


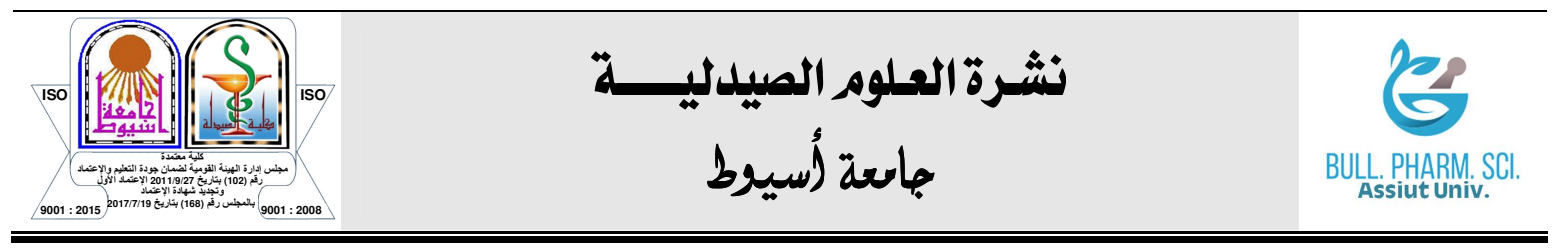

\section{وضع الصيدلة المجتمعية في مصر : هل الصيليات المجتمعية جاهزة لتقديم خدمات التمبية الصيدلة الأكلينيكية على ملى المستوى الوطني؟}

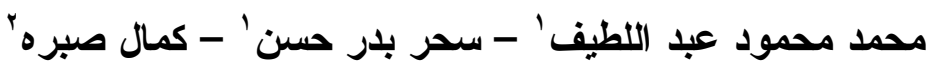
'قسم الصيدلة الإكلينينيكة ، كلية الصيدلة ، جامعة أسيوط ، أسيوط ، مصر

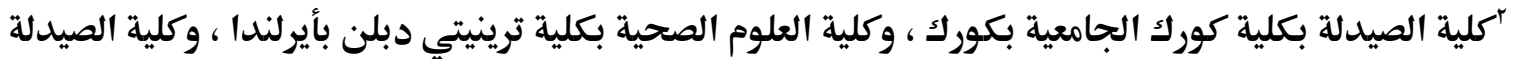
بجامعة المستقبل بمصر

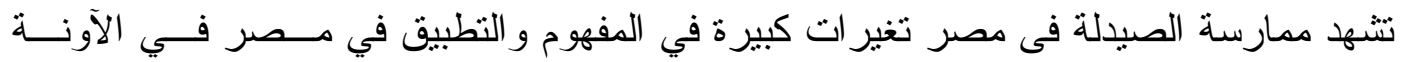

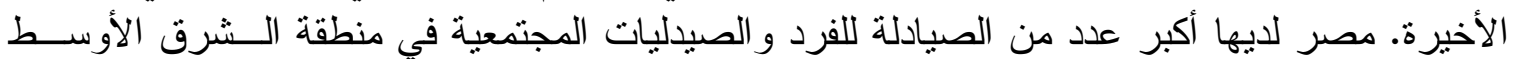

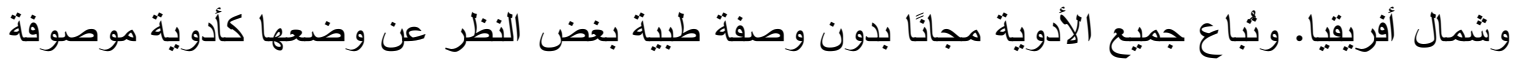

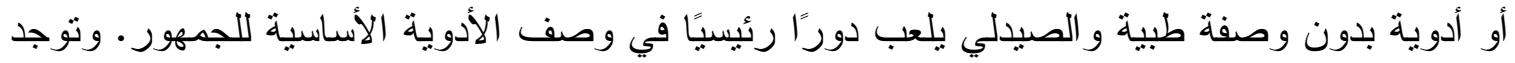

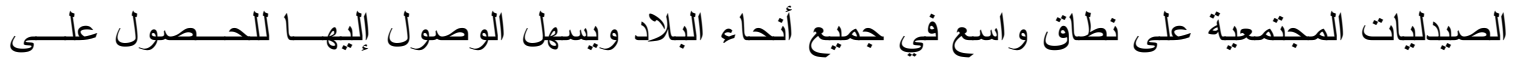

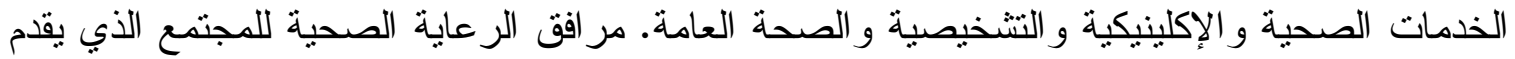

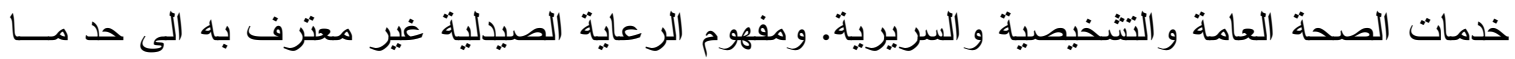

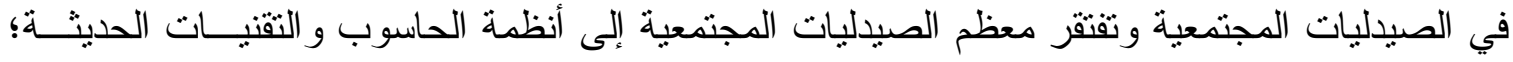

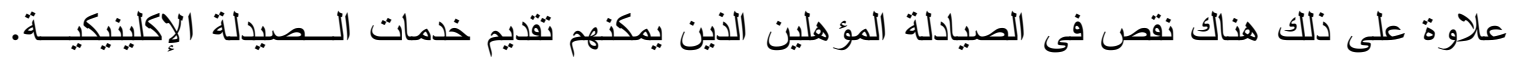

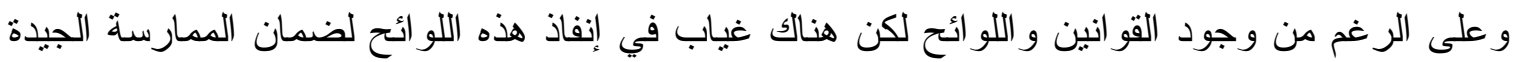

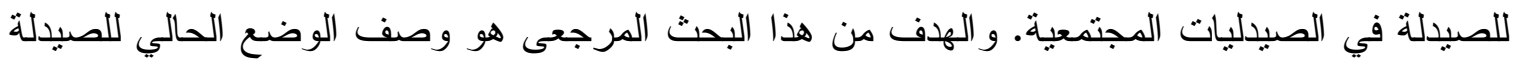
المجتمعية في مصر ومدى استعدادها لتقديم خدمات الصيدلة الإكلينيكية. 